\title{
PERCEPÇÃO E RESPOSTAS GERENCIAIS AO RISCO: UM ESTUDO SOBRE OS PRODUTORES DE LEITE DO PROGRAMA DE DESENVOLVIMENTO DA PECUÁRIA LEITEIRA DA REGIÃO DE VIÇOSA - MG'
}

\author{
Sônia Maria Leite Ribeiro do Vale ${ }^{2}$ \\ Vanessa da Fonseca Pereira ${ }^{3}$ \\ Antônio Carlos Lima Neto ${ }^{4}$ \\ Júlio César Oliveira Sant'Anna
}

\begin{abstract}
Resumo - O setor agropecuário apresenta características peculiares, universais e desfavoráveis, as quais tornam seus participantes mais sujeitos aos riscos e aumentam a complexidade da tomada de decisão. Apesar disso, há pouco conhecimento acerca da percepção dos próprios produtores rurais em relação ao risco de sua atividade. Com base em uma pesquisa realizada na Zona da Mata de Minas Gerais, este trabalho apresenta a visão de um grupo de produtores de leite em relação ao risco a que estão expostos e, também, descreve as ferramentas utilizadas por eles como respostas gerenciais a essa exposição. Inicialmente, os produtores responderam sobre a importância das várias fontes de risco do seu negócio e, em seguida, citaram os métodos utilizados para gerenciar essas fontes. Os resultados apontam a ausência de gestão formal do risco, a qual tem sido compensada, até então, pela experiência dos produtores e pelo conseqüente conhecimento do mercado.
\end{abstract}

Palavras-chave: risco agropecuário, gestão, informação.

\footnotetext{
Trabalho desenvolvido com o apoio da FAPEMIG. Recebido em: 12/02/2007. Aceito em: 30/04/2007.

Professora do Departamento de Economia Rural da UFV. E-mail: smleite@ufv.br

Mestranda do Departamento de Economia Rural da UFV. E-mail: vanessajf@ acessa.com

4 Graduado em Agronomia pela UFV.

5 Técnico do Departamento de Economia Rural da UFV.
} 


\section{Introdução}

O acirramento da competitividade tem atingido todos os setores da economia, com maior ou menor intensidade. Sabe-se que a abertura dos mercados e o aumento da velocidade de circulação das informações impõem determinadas exigências às organizações para sua sobrevivência e, mais além, para a geração de resultados positivos. De acordo com Portugal (2005), a cadeia produtiva do leite passou por profundas transformações a partir da década de 1990, destacando-se o aumento expressivo da produtividade, a melhoria de qualidade, as mudanças na logística e na relação entre o produtor e a indústria, a redução de importações e o aumento das exportações. As principais causas das transformações da cadeia produtiva do leite apontadas por Gomes (2001) incluem a desregulamentação do mercado de leite a partir de 1991; a maior abertura da economia brasileira para o mercado internacional, em especial a criação do Mercosul; e a estabilização dos preços no País.

Nesse contexto de mudanças, questões tradicionalmente discutidas, como preço, custo de produção e margens de comercialização, e novas questões, como gestão da informação, mudanças tecnológicas, exportação e variação do câmbio, desafiam ainda mais os agentes da cadeia do leite.

No topo da hierarquia das exigências para os produtores encontra-se a necessidade de eficiência e eficácia da empresa, não só em relação às questões produtivas, mas também mercadológicas e financeiras, por exemplo. Assim, o gerenciamento da empresa é uma atividade essencial, uma vez que é o meio para o alcance dos objetivos do produtor, tendo em vista a situação do mercado e o contexto interno a esta. Ademais, o sucesso da atividade gerencial é extremamente dependente das informações que a empresa possui, de modo que, à medida que estas representam a realidade de maneira mais fidedigna, as ações administrativas possuem maiores chances de obter sucesso.

Todavia, de acordo com Vale (2005), o setor agropecuário apresenta características peculiares universais, desfavoráveis e diferentes das 
Sônia Maria Leite Ribeiro do Vale, Vanessa da Fonseca Pereira, Antônio Carlos Lima Neto \& Júlio César Oliveira Sant’Anna

verificadas em outros setores da economia, as quais possuem extrema importância para a análise da tomada de decisão. Essas características são responsáveis por fazer com que o contexto das atividades agropecuárias apresente proporção maior de risco para aqueles que trabalham no setor ${ }^{6}$.

Há muitas fontes de risco para a produção agrícola, as quais advêm da natureza imprevisível do clima e da incerteza sobre o desempenho de culturas ou de atividades de pecuária, isto é, incidentes como doenças e pragas e outras, como a sazonalidade da produção, além de outros fatores imprevisíveis. Além disso, os preços de insumos e produtos agrícolas raramente são conhecidos no tempo em que o produtor precisa decidir sobre quanto de cada insumo usar e sobre quanto de vários produtos irá produzir. Ademais, praticamente todos os produtores estão expostos a mercados imprevisíveis para insumos e produtos, de modo que o fator preço ou risco de mercado é, freqüentemente, significativo e pode aumentar com o passar do tempo.

Soma-se a isso a característica de perecibilidade inerente à grande parte dos produtos, a qual aumenta ainda mais a suscetibilidade do setor produtivo, posto que impõe uma restrição acerca do tempo em que a empresa pode colocar sua oferta no mercado. Há também o risco financeiro, que resulta das fontes utilizadas para financiar o negócio da empresa, em decorrência, por exemplo, de variações na taxa de juros (Hardaker, 1998).

Em contrapartida, há uma representativa variedade de ferramentas que podem ser utilizadas para administração e minimização de riscos em empresas agropecuárias, as quais são descritas minuciosamente por Harwood et al. (1999). Esses autores afirmam que os produtores agrícolas devem decidir sobre a escala de sua operação, o grau de controle sobre os recursos produtivos, a alocação de recursos entre os empreendimentos

6 Vale esclarecer que se considera, de acordo com Harwood et al. (1999), o risco como uma incerteza que afeta o bem-estar do indivíduo, sendo freqüentemente associado à adversidade e perda, cujo gerenciamento envolve escolher entre alternativas para redução dos seus efeitos. 
e quando utilizar seguros. Essas decisões são tomadas com o objetivo de reduzir os níveis de risco do negócio.

Embora esteja claro que o risco e a incerteza desempenham importante papel na agricultura, Boggess (1985) afirma que muito pouco é conhecido sobre a percepção dos produtores acerca do assunto. Nesse sentido, Hardaker (1998) considera certo que os produtores rurais têm consciência da existência do risco e têm se adequado à sua própria maneira na condução de suas propriedades. Todavia, com poucas notáveis exceções, ainda é pequeno o uso de métodos formais de análise de risco na agricultura.

Por outro lado, apesar da existência de uma vasta possibilidade de ferramentas e estratégias de redução de risco, na prática, os produtores fazem uso de um número limitado, visto que elas podem ser inapropriadas em função do tamanho da propriedade, do tipo, do local ou de sua estrutura. A pesquisa de Martin (1996), por exemplo, sugere que o uso de diferentes estratégias de gerenciamento de risco na agricultura varia de acordo com a realidade climática, a natureza do produto, fatores de mercado e estrutura do mercado, a dedicação do produtor ao ciclo produtivo, considerações do ajuste dinâmico ao risco e o ambiente regulador.

Nesse sentido, é importante realizar algumas considerações mais específicas acerca do grupo de produtores abordados no presente estudo. De acordo com Gomes (2005), a administração dos estabelecimentos produtores de leite em Minas Gerais é tipicamente familiar, com poucas exceções de administradores contratados, uma vez que as empresas rurais, em geral, não possuem escala suficiente para o pagamento de um administrador, dado o elevado custo fixo médio da atividade. Com isso, a utilização de técnicas formais de planejamento e gerenciamento acaba sendo restrita. Essa observação é ratificada pelo autor quando ele afirma que a maioria dos produtores, em 2005, não possuía metas para a produção de leite, produtividade, receitas e despesas. Além disso, o autor relata que a pecuária leiteira é a principal atividade econômica dos produtores 
Sônia Maria Leite Ribeiro do Vale, Vanessa da Fonseca Pereira,

Antônio Carlos Lima Neto \& Júlio César Oliveira Sant’Anna

de Minas Gerais. Constata-se, então, a reduzida diversificação dos produtores, posto que são poucos aqueles que se dedicam a outras atividades, sejam rurais ou não.

O autor supracitado afirma ainda que, em média, os produtores do Estado possuem 20 anos de experiência com a atividade de pecuária leiteira. Esse elevado tempo de dedicação ao setor reduz os riscos de prejuízo, de modo que é pouco comum a ocorrência de falências entre os produtores de leite, em virtude da experiência acumulada no mercado.

Pelo exposto, este trabalho visou apresentar um estudo acerca da visão dos produtores de leite da Zona da Mata de Minas Gerais quanto ao risco da sua atividade. A escolha apoiou-se no importante papel desempenhado pela região na pecuária leiteira nacional. De acordo com dados do Instituto Brasileiro de Geografia e Estatística - Pesquisa Pecuária Municipal (IBGE-PPM), no ano de 2005, o Estado de Minas Gerais foi responsável por cerca de $28 \%$ da produção leiteira nacional e a Zona da Mata mineira respondeu por $9,90 \%$ da produção no Estado. Além disso, a Zona da Mata é a segunda mesorregião mineira em termos de produtividade por vaca. Ressalta-se que, apesar da relevância do assunto, não há estudos sobre o gerenciamento do risco pelo setor produtivo sob a ótica dos próprios tomadores de decisão. Destarte, esperase contribuir para o conhecimento do tema e, ainda, para a utilização das informações em benefício dos próprios produtores, no que diz respeito às suas práticas gerenciais.

Neste trabalho pretendeu-se identificar a visão que os produtores de leite da Zona da Mata mineira possuem acerca do risco e como o gerenciam. Especificamente, pretendeu-se identificar e ordenar as fontes de risco para os produtores; identificar as estratégias de gerenciamento de risco utilizadas; e definir estratégias de gerenciamento de risco adequadas aos produtores em análise. 


\section{Referencial Teórico}

De acordo com Pindyck (1994), para a descrição do risco de forma quantitativa, é necessário o conhecimento das possíveis consequiências de uma determinada atividade, bem como qual a probabilidade de cada possível consequiência. Nesse sentido, a probabilidade é uma medida importante, visto que indica a possibilidade de que um determinado resultado ocorra. Há a interpretação objetiva da probabilidade, a qual se fundamenta na frequiência com a qual determinados eventos tendem a ocorrer, e a interpretação subjetiva, a qual consiste em uma percepção de que um determinado resultado ocorrerá. A primeira interpretação requer a existência de experiência anterior, baseando-se na frequiência com que um determinado resultado tenha realmente ocorrido no passado. Já a segunda é dependente da pessoa que a define, ou seja, em função das informações adquiridas acerca do assunto e da forma como essas são interpretadas, e cada indivíduo define a probabilidade que julgar mais adequada para o evento.

O autor afirma ainda que, independentemente da interpretação aplicada, a probabilidade sempre é utilizada durante o cálculo de duas importantes medidas para a descrição e comparação de escolhas de risco, como o valor esperado e a variabilidade para os possíveis resultados. A primeira informa a tendência central, isto é, o desfecho que, na média, se espera que ocorra; já a segunda apresenta o tamanho da diferença entre os desfechos reais e os desfechos esperados, a qual se chama desvio e pode ser positiva ou negativa. Ambas as informações apresentam contribuição essencial para a tomada de decisão diante de situações de risco.

Entretanto, sabe-se que a tomada de decisão depende, ainda, da forma como o indivíduo enxerga e avalia os resultados de risco. De acordo com Varian (1999), as preferências de consumo em diferentes estados da natureza dependem das crenças do indivíduo sobre a probabilidade de ocorrência de cada estado. Para descrição dessas preferências, faz-se 
Sônia Maria Leite Ribeiro do Vale, Vanessa da Fonseca Pereira,

Antônio Carlos Lima Neto \& Júlio César Oliveira Sant'Anna

uso da função de utilidade, a qual depende do nível de satisfação atingido a partir de dado nível de consumo e das probabilidades de ocorrência de cada resultado. Nesse sentido, as pessoas diferem em sua disposição para assumir riscos, sendo categorizadas em três grupos distintos: avessos, indiferentes e apreciadores do risco.

Para o indivíduo que apresenta aversão ao risco, a utilidade marginal de consumo reduz à medida que sua renda aumenta. Nesse caso, a utilidade esperada de riqueza é inferior à utilidade da riqueza esperada, ou seja, o indivíduo prefere ter o valor esperado de sua riqueza do que apostar. No outro extremo, há a propensão ao risco, quando a utilidade marginal do consumo eleva-se a partir de um aumento na renda. Esse grupo caracteriza-se por preferir a distribuição aleatória da riqueza ao seu valor esperado. O caso intermediário é o da função de utilidade linear, quando a pessoa se mostra indiferente entre eventos garantidos e eventos nãogarantidos com o mesmo nível de utilidade esperada, ou seja, a utilidade esperada da riqueza é exatamente igual à utilidade do seu valor esperado. Nesse caso, não há preocupação em absoluto com os riscos aos quais sua riqueza esteja sujeita, preocupando-se apenas com seu valor esperado.

A Figura 1 apresenta, graficamente, uma função de utilidade côncava para o consumidor avesso ao risco, de modo que sua inclinação torna-se cada vez mais plana à medida que a riqueza se eleva. Já o consumidor propenso ao risco possui uma função de utilidade convexa, e sua inclinação torna-se cada vez mais íngreme à medida que ocorre aumento da riqueza. 


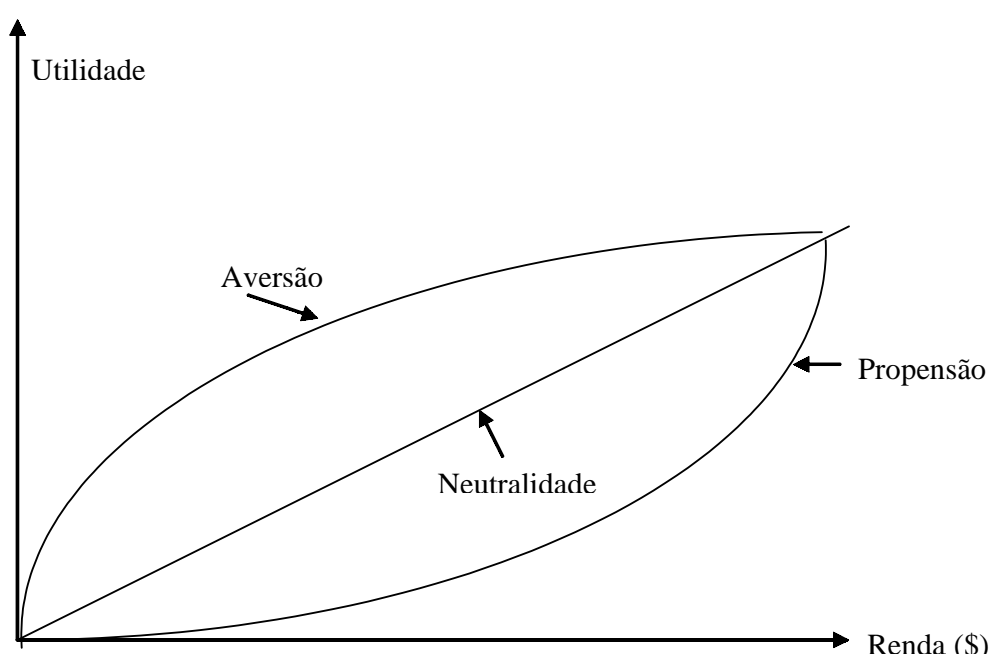

Figura 1 - Comportamento perante o risco e função utilidade.

Fonte: Adaptado de Clemen (1990).

Patrick et al. (1985) afirmaram que os critérios de decisão acerca da gestão do risco variam de acordo com a região geográfica e com o tipo da propriedade, o que implica a impossibilidade de criação de técnicas padronizadas de modelagem do risco. Além disso, esses autores concluíram que um modelo de análise de risco na agricultura deve abordar, pelo menos, aspectos produtivos, mercadológicos e financeiros, em vez de considerar somente a variável preço e produção, o que subestimaria a importância do risco no processo de tomada de decisão.

Esse mesmo trabalho ressalta que o gerenciamento de informação para a tomada de decisões no âmbito mercadológico e financeiro é uma restrição significativa ao sucesso de muitos produtores. Por fim, os autores afirmam que a estabilidade de variáveis macroeconômicas — como a inflação, as taxas de juros, as políticas agrícolas e a regulamentação governamental - é muito importante para melhorar a posição dos produtores em relação ao risco. 
Sônia Maria Leite Ribeiro do Vale, Vanessa da Fonseca Pereira, Antônio Carlos Lima Neto \& Júlio César Oliveira Sant’Anna

Assim como na pesquisa supracitada, Jolly (1983) ressalta a importância das informações para o processo de tomada de decisões. $\mathrm{O}$ autor assegura que o gerenciamento de risco envolve uma expansão da base de informações sobre as quais as decisões apóiam-se e prossegue afirmando que o processo de escolha mais bem estruturado pode não ser efetivo se for baseado em estimativas incompletas ou não confiáveis acerca do problema em questão.

Jolly (1983) relata que um administrador pode responder ao risco de duas formas gerais: através da tentativa de controlar a exposição ao risco ou de controlar o seu impacto sobre o negócio. O controle da exposição engloba a seleção e diversificação dos empreendimentos, atividades de marketing, adoção de seguros, criação de programas governamentais e definição do volume e da escala de operação. Já para a redução do impacto, o autor considera estratégias que exercem influência sobre a capacidade do negócio de suportar adversidades ou explorar eventos favoráveis. Nesse segundo grupo encontram-se a escolha da estrutura financeira, como a manutenção de reservas em caixa, por exemplo; a organização do negócio e acordos operacionais; o aumento de produtividade e eficiência; e o sistema de impostos.

Por sua vez, o trabalho de Martin (1993) classifica as respostas ao risco como de produção, marketing ou financeiras, e as descreve sucintamente. As respostas de produção englobam selecionar os empreendimentos que reconhecidamente apresentem baixa variação nos retornos, ou selecionar uma região na qual os retornos para os produtores são mais estáveis. A diversificação dos empreendimentos, freqüentemente utilizada, também pode ser uma forma apropriada de reduzir o risco, e a dispersão geográfica da atividade produtiva é uma opção adicional. Uma mudança nas práticas técnicas pode servir como esquemas informais de seguro, a qual pode incluir um excesso no investimento em maquinário, a manutenção de reservas de alimento, as medidas de precaução quanto à saúde dos animais e das plantas, como aplicações preventivas de inseticidas e antibióticos, o cultivo de diversas variedades de lavouras e o investimento em irrigação suplementar. 
Além disso, a autora aborda a substituição do trabalho por capital como uma forma de evitar problemas em função das questões trabalhistas. Alternativamente, um sistema de incentivos e recompensas bem estruturado é capaz de reduzir os riscos advindos dessa fonte.

Já em relação às respostas de marketing, inclui-se a seleção de empreendimentos com mais baixa expectativa de oscilação de preços e a disseminação da produção ao longo do tempo escalonando-a ou mesmo através dos estoques. Os contratos futuros também se encontram nesse grupo, de modo que permitem que o nível produtivo e, em alguns casos, o preço sejam conhecidos antes da entrega da produção. De acordo com Harwood et al. (1999), a adoção de contratos pode abordar questões produtivas, os quais usualmente especificam em detalhes questões relativas à qualidade e à quantidade a serem transacionadas. Os autores fazem referências também aos contratos de marketing, nos quais são estabelecidos os preços e as formas de descontos antes que a produção tenha sido realizada.

Nesse contexto, embora sejam recentes algumas experiências com o uso de contratos de compra e venda de leite, suas vantagens para proteger os interesses de ambas as partes, vendedor e comprador, já podem ser percebidas, conforme afirmam Gomes e Leite (2001). Sob a visão da indústria, a utilização de contratos é vantajosa, pois permite o estabelecimento de parâmetros indicadores de qualidade desejáveis, bem como a exigência de maior regularidade no volume de leite entregue ao longo do ano. Por sua vez, do lado dos produtores, a definição de cláusulas relativas a quantidade, qualidade, preços e prazos para recebimento protege-os das incertezas relativas à sua renda, assegurando melhores condições para o planejamento e a condução de seu negócio.

Mais uma vez a importância da informação é abordada, uma vez que Martin (1993) afirma que uma melhora na qualidade das informações sobre os preços e as necessidades do mercado também é um fator que colabora para a redução do risco. 
Sônia Maria Leite Ribeiro do Vale, Vanessa da Fonseca Pereira, Antônio Carlos Lima Neto \& Júlio César Oliveira Sant’Anna

Por fim, as respostas de cunho financeiro podem incluir a manutenção de liquidez adicional, por meio de ativos mais líquidos e adequando-se a estrutura de pagamento de débitos à estrutura da entrada das receitas. $\mathrm{O}$ aumento da relação entre o capital e o ativo total, por meio de injeção de capital, seja de fonte interna ou externa, também contribui para a redução do risco financeiro. Outras formas são a realização de leasing e a adoção dos mais variados tipos de seguros. Adicionalmente, o investimento de capital fora da organização produtiva, o qual pode ser financeiro ou não, é uma outra maneira de diversificação que pode ser adotada.

De acordo com Harris (1990), o primeiro trabalho econômico acerca da utilização de conhecimento na tomada de decisão foi realizado por Knight, em 1921, o qual definiu três estágios de conhecimento, a saber: conhecimento perfeito, risco e incerteza. A distinção entre os dois últimos foca principalmente na diferença entre probabilidades objetivas e subjetivas. O risco associa-se com uma probabilidade objetiva, a qual é baseada nas características da situação ou nas observações das frequiências dos resultados de experimentos já repetidos - assim como a derivação da possibilidade de chuva a partir de dados históricos.

Por outro lado, incerteza somente é definida por uma probabilidade subjetiva, ou seja, as probabilidades não são conhecidas em nenhum senso objetivo e coloca-se algum adivinhador para dizer seu valor. Um exemplo de probabilidade subjetiva são os retornos da plantação de uma nova espécie. Nas definições mencionadas está implícita a idéia de que, quanto maior a variação nos resultados, maior o risco.

$\mathrm{O}$ autor apresenta uma perspectiva diferente sobre o tema ao dividi-lo em risco do negócio e risco financeiro. O primeiro é definido como inerente à firma, independentemente do modo como as operações são financiadas. O segundo é conseqüência das obrigações financeiras fixas associadas aos financiamentos de débitos e de caixa. Assim, o risco total é uma combinação das duas fontes, somando-as. 
No que diz respeito à forma como os indivíduos atuam perante o risco, Harris (1990) aponta as três categorias de atitude supramencionadas: aversão, neutralidade e preferência. Nesse contexto, essas características interferem no posicionamento das organizações, tanto na forma de atuação no mercado quanto em relação às metas estabelecidas. Para Martin (1996), o objetivo do gerenciamento do risco é reduzir as chances de uma situação vulnerável em busca de atingir a mais alta possibilidade de retorno consistente com a atitude do indivíduo em relação ao risco.

\section{Referencial Analítico}

Em um primeiro momento, são analisadas as fontes de risco citadas pelos produtores na pesquisa. Pretende-se mencioná-las e, em seguida, comparar com aquelas que foram apontadas como as mais marcantes pelos trabalhos utilizados como base para este estudo. Essa etapa é essencial para a pesquisa, uma vez que traz à tona a visão que os próprios produtores possuem do negócio em que atuam. Com isso, observa-se qual o nível de risco o produtor associa à sua atividade, comparando-se os resultados com as afirmações anteriormente realizadas, as quais colocam a atividade agropecuária em um nível de risco mais elevado que as demais atividades produtivas.

A mesma comparação é realizada em relação às estratégias de gestão do risco, ou seja, a partir dos dados obtidos na pesquisa com os produtores de leite da Zona da Mata de Minas Gerais, é feita ainda uma exposição das posturas estratégicas que têm sido adotadas pelo setor para minimizar os efeitos negativos sobre o negócio. Essa etapa está intimamente relacionada à primeira, posto que a partir das fontes consideradas relevantes para os produtores abordados pretende-se dizer quais delas são gerenciadas com maior freqüência.

O modelo utilizado para análise do gerenciamento do risco é baseado no conceito de Hardaker (1998), o qual consiste em uma aplicação sistemática de políticas gerenciais, procedimentos e práticas às tarefas de 
Sônia Maria Leite Ribeiro do Vale, Vanessa da Fonseca Pereira, Antônio Carlos Lima Neto \& Júlio César Oliveira Sant'Anna

identificação, análise, avaliação, tratamento e monitoramento do risco. Trata-se de uma abordagem descritiva de todo o processo decisório em relação às ameaças às quais os produtores estão sujeitos. Com base na descrição feita pelo autor de cada uma dessas etapas e nos demais trabalhos supracitados, descreve-se a gestão do risco adotada pelos produtores em questão, despendendo maior atenção às fases de identificação e gerenciamento (Figura 2).

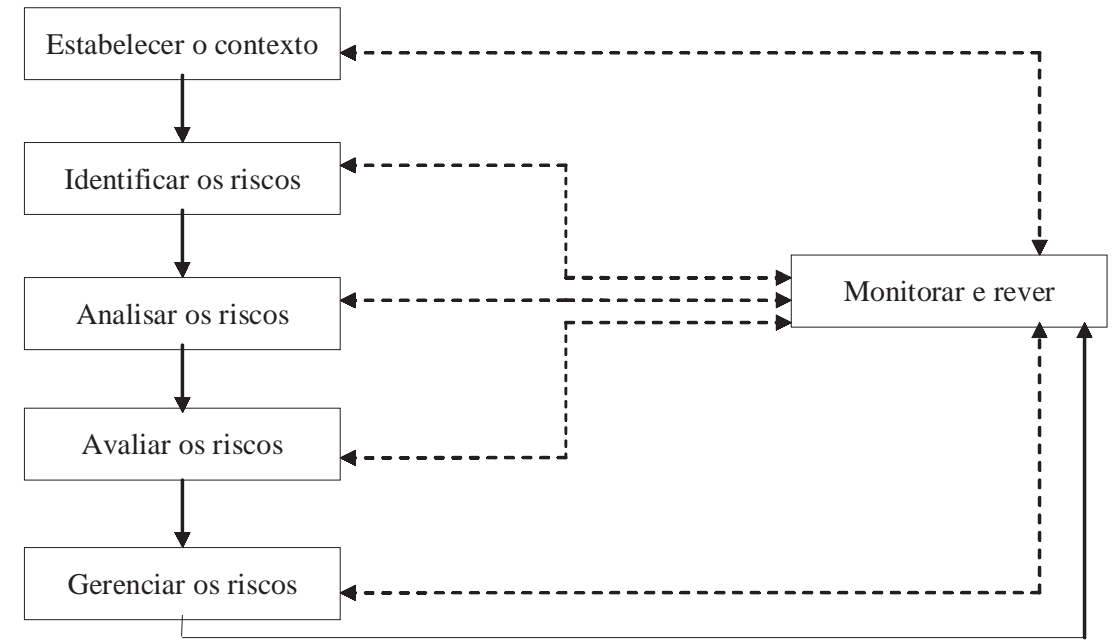

Figura 2 - Resumo dos passos do gerenciamento de risco. Fonte: Hardaker (1998).

A primeira etapa - estabelecimento do contexto - consiste na instituição do cenário no qual a organização produtiva está inserida e é realizada em termos de três aspectos, a saber: estratégicos, organizacionais e de gerenciamento de risco. Os primeiros referem-se às relações entre a organização e o ambiente, identificando-se seus pontos fortes e fracos e as ameaças e oportunidades. Os organizacionais dizem respeito à própria administração interna e aborda o processo de definição e comunicação de metas e objetivos e a divisão de responsabilidades entre os funcionários. 
É importante notar que, de acordo com Hardaker (1998), para qualquer organização, seja de grande porte, empresa governamental ou mesmo de agricultura familiar, o gerenciamento de risco é, ou pelo menos deveria ser, uma parte da boa gerência, o que torna a análise desses aspectos organizacionais coerente com o tema em questão.

Quanto à identificação, cabe ressaltar que há, de acordo com o autor, uma lista infindável de possíveis fontes de risco, de modo que é importante perceber se as fontes consideradas pelos respondentes realmente possuem efeito significativo sobre o alcance da melhor performance da firma, visando assegurar que todas essas fontes de significância sejam levadas em conta pelos produtores.

Já a análise do risco pode ser dividida em duas etapas: consideração das chances de ocorrência do risco e avaliação das consequiências, dadas as práticas gerenciais utilizadas. Em geral, tal análise ocorre informalmente, visto que os produtores pensam em termos de uma situação ser "muito provável" ou "pouco provável", ou ainda em termos de determinados eventos serem "sérios" ou "catastróficos" em relação às suas consequiências. Entretanto, Hardaker (1998) discorre acerca de uma análise sistemática, a qual inclui uso de dados probabilísticos e atenção às informações difundidas pelos especialistas na área com a qual os produtores trabalham.

A etapa de avaliação é dependente diretamente da anterior. A partir da identificação de uma fonte de risco, faz-se necessário considerar as atitudes dos tomadores de decisão, tanto interna quanto externamente à organização. Internamente, a questão-chave é o grau de aversão ao risco apresentado pelo condutor do processo decisório e, externamente, é necessário definir o grau de ameaça do público externo em reação a algum mau resultado da empresa.

O gerenciamento do risco consiste na identificação do conjunto de opções para lidar com cada fonte particular e, então, avaliar tais opções, selecionar a mais adequada e colocá-la em prática. Uma vez decidido e 
Sônia Maria Leite Ribeiro do Vale, Vanessa da Fonseca Pereira,

Antônio Carlos Lima Neto \& Júlio César Oliveira Sant'Anna

implementado o gerenciamento, é importante que este seja mantido em prática. Entretanto, o autor observa que determinadas ações implementadas podem ser insatisfatórias em razão de dependerem de informações que, muitas vezes, apresentam-se incompletas ou imperfeitas. Assim, é importante que sejam realizados o monitoramento e a revisão dos planos com o intuito de realizar ajustes necessários, continuamente.

A análise dos dados é baseada na freqüência simples das respostas obtidas e apresentada em forma tabular.

Utilizaram-se, nesta pesquisa, dados primários coletados a partir de questionários aplicados a uma amostra representativa de produtores de leite, da Zona da Mata de Minas Gerais. Trata-se de produtores participantes do Programa de Desenvolvimento da Pecuária de Leite da Região de Viçosa (PDPL-RV), os quais totalizaram 21 respondentes.

\section{Resultados e Discussão}

De acordo com o modelo analítico proposto e descrito anteriormente, a primeira etapa do processo de gerenciamento de risco consiste na definição do contexto. De acordo com as respostas obtidas na pesquisa e apresentadas na Tabela 1, verifica-se que o grupo estudado considera a atividade de pecuária leiteira significativamente arriscada, uma vez que $95,2 \%$ dos entrevistados a relacionaram a um grau de risco pelo menos moderado. 
Tabela 1 - Percepção dos produtores acerca da intensidade de risco da pecuária leiteira - Minas Gerais, 2005

\begin{tabular}{cc}
\hline Intensidade do risco & Participação percentual (\%) \\
\hline Pequena & 4,8 \\
\hline Moderada & 47,6 \\
\hline Grande & 33,3 \\
\hline Muito grande & 14,3 \\
\hline Total & 100,0 \\
\hline
\end{tabular}

Fonte: Dados da pesquisa.

Nota-se, portanto, uma concordância entre a opinião dos produtores e as afirmativas feitas anteriormente acerca do elevado grau de risco ao qual o agronegócio está sujeito. Apesar disso, a pesquisa demonstrou que a escolha pela pecuária leiteira como opção dentro do portfólio de atividades econômicas existentes no agronegócio foi uma decisão própria de 85,7\% dos produtores.

Ainda quanto à definição do ambiente em que atuam, buscou-se apreender em qual posição os produtores se enxergam em relação ao nível de risco ao qual estão sujeitos, comparativamente aos demais produtores da região. Observou-se que $57,2 \%$ dos pecuaristas abordados consideraram que os seus riscos são os mesmos quando comparados aos de outros produtores da região, $23,8 \%$ acham que os seus riscos são maiores quando comparados aos de outros produtores e 19,0\% afirmaram que seus riscos são menores, nessa mesma comparação.

A segunda etapa do modelo é a identificação dos riscos, a qual é enfatizada neste trabalho. Inicialmente, buscou-se levantar o conceito de risco que os entrevistados possuem, por meio de uma questão aberta, de modo que não houvesse opções que poderiam ser uma restrição à resposta do produtor. Embora não tenham sido apresentadas opções de escolha, os resultados apresentaram significativa concordância: 33,3\% dos respondentes conceituaram o tema como sendo as oscilações 
Sônia Maria Leite Ribeiro do Vale, Vanessa da Fonseca Pereira,

Antônio Carlos Lima Neto \& Júlio César Oliveira Sant’Anna

desfavoráveis mercadológicas e/ou climatológicas e 23,8\% conceituaram risco como a incerteza de retorno financeiro. Houve outras respostas, porém sem frequiência de destaque.

Também por meio de uma questão aberta, observou-se que $66,7 \%$ dos empresários rurais em estudo consideram as oscilações de preço do produto a principal fonte de risco para a atividade, a qual consiste em um aspecto mercadológico. Em seguida, a descapitalização e o manejo inadequado foram apontados, cada um, por 9,5\% dos entrevistados como a principal ameaça ao negócio.

Ao questionar os produtores sobre o grau de importância dado às diversas fontes de riscos, verifica-se na Tabela 2 que há uma variabilidade grande, em que os três principais itens por eles considerados extremamente importantes são, na ordem de maior frequiência: mudança no preço do leite, mudança no preço dos insumos e falta de chuvas. Os dois primeiros referem-se a questões de cunho mercadológico, dependentes de elos da cadeia produtiva a montante e a jusante, quer sejam fornecedores de insumos, quer compradores do produto. Além da falta de chuva, houve outros aspectos climatológicos relatados como tendo mediana importância, a saber: o risco de excesso de chuva e de outros fatores climáticos, como o veranico. Por sua vez, as fontes de risco consideradas menos importantes foram problemas familiares, mudança no preço da terra e acidente pessoal e problemas de saúde. 
Tabela 2 - Demonstrativo das fontes de riscos e grau de importância a elas atribuído na opinião dos produtores rurais - Minas Gerais, 2005

\begin{tabular}{|c|c|c|c|c|c|}
\hline \multirow{2}{*}{$\begin{array}{c}\text { DESCRIÇÃO DAS FONTES } \\
\text { DE RISCO }\end{array}$} & \multicolumn{5}{|c|}{ GRAU DE IMPORTÂNCIA (valores percentuais) } \\
\hline & $\begin{array}{c}\text { Sem } \\
\text { importância }\end{array}$ & $\begin{array}{l}\text { Levemente } \\
\text { importante }\end{array}$ & Moderada & Importante & $\begin{array}{c}\text { Extremamente } \\
\text { importante }\end{array}$ \\
\hline Mudança da taxa de juros & 33,3 & 23,8 & 19,0 & 9,5 & 14,3 \\
\hline Mudança do preço da terra & 71,4 & 14,3 & 9,5 & 4,8 & ----- \\
\hline Mudança de preço do leite & ------- & ------ & 4,8 & 4,8 & 90,5 \\
\hline Mudança de preços dos insumos & ------- & 4,8 & 4,8 & 4,8 & 85,7 \\
\hline $\begin{array}{l}\text { Mudanças das políticas } \\
\text { econômicas }\end{array}$ & 19,0 & 23,8 & 33,3 & 14,3 & 9,5 \\
\hline Falta de chuva & $\begin{array}{ll}----- \\
\end{array}$ & 4,8 & 4,8 & 33,3 & 57,1 \\
\hline Excesso de chuva & 4,8 & 4,8 & 14,3 & 33,3 & 42,9 \\
\hline $\begin{array}{l}\text { Outros fatores climáticos } \\
(\text { veranico,...) }\end{array}$ & 4,8 & 4,8 & 19,0 & 38,1 & 33,3 \\
\hline Desastres, como incêndios & 28,6 & 19,0 & 14,3 & 14,3 & 23,8 \\
\hline Pragas nas pastagens & 19,0 & 33,3 & 23,8 & 4,8 & 19,0 \\
\hline Doenças que afetam os animais & 9,5 & 9,5 & 14,3 & 33,3 & 33,3 \\
\hline $\begin{array}{l}\text { Intoxicação alimentar nos } \\
\text { animais }\end{array}$ & 14,3 & 33,3 & 4,8 & 19,0 & 28,6 \\
\hline $\begin{array}{l}\text { Exigência de melhoria na } \\
\text { qualidade do leite }\end{array}$ & 19,0 & 23,8 & 14,3 & 23,8 & 19,0 \\
\hline Risco com mão-de-obra & 23,8 & 19,0 & 14,3 & 14,3 & 28,6 \\
\hline Risco com ladrões & 38,1 & 33,3 & 14,3 & $\begin{array}{ll}------ \\
\end{array}$ & 14,3 \\
\hline Risco de problemas familiares & 76,2 & 4,8 & 9,5 & ------- & 9,5 \\
\hline $\begin{array}{l}\text { Acidente pessoal e problemas de } \\
\text { saúde }\end{array}$ & 47,6 & 4,8 & 23,8 & 14,3 & 9,5 \\
\hline
\end{tabular}

Fonte: Dados da pesquisa.

Indagados a respeito dos principais problemas climáticos na região que poderiam influenciar o desempenho da atividade leiteira, os entrevistados indicaram, em primeiro lugar, as chuvas e a seca, ambos com 52,4\% das observações, seguidos pela estiagem, com $38,1 \%$, e, por fim, os ventos fortes, com $23,8 \%$. Constatou-se que em $71,4 \%$ das propriedades já ocorreu algum tipo de problema climático, e o maior índice de ocorrências é de secas, com 23,8\% das observações. Em relação à ocorrência de fenômenos climáticos que tenham resultado em problemas, 93,34\% dos produtores afirmaram ter tido perdas em função dessas manifestações da natureza e que o período de maior ocorrência (com 28,6\% das respostas) foi o ano de 2004 . 
Sônia Maria Leite Ribeiro do Vale, Vanessa da Fonseca Pereira, Antônio Carlos Lima Neto \& Júlio César Oliveira Sant’Anna

Em relação à terceira fase do modelo utilizado para estudo do gerenciamento do risco - a análise -, a pesquisa não identificou utilização de métodos formais e sistematizados ou a aplicação de técnicas probabilísticas. Assim, observou-se que a definição da chance de ocorrência de determinado evento e suas possíveis consequiências baseiase na experiência anterior dos produtores, no histórico da atividade. Isso porque as maiores ameaças consideradas por eles são aqueles eventos que ocorreram com maior frequiência e geraram maiores perdas, ou seja: as oscilações de preço, as quais são comuns no mercado em questão, e os fenômenos climáticos, os quais já atingiram a grande maioria das propriedades.

A avaliação dos riscos é dependente da posição que o tomador de decisão adota diante de uma situação de risco, ou seja, se ele se apresenta avesso, neutro ou propenso ao risco. Utilizou-se uma questão para identificar o comportamento típico acerca da realização de investimentos. As duas opções mais frequientes foram a realização de aplicações que resultem em ganho médio, sujeitas a um nível de risco igualmente médio, e aplicações que mantenham a situação atual. Cada uma das respostas foi dada por 33,3\% dos empresários rurais. Cabe ressaltar que somente um entrevistado, o que equivale a 4,76\% da amostra, afirmou optar pela realização de investimentos que apresentem baixo ganho constante, mas sem estar sujeito a qualquer nível de risco. Por outro lado, o mesmo percentual de respostas foi obtido para a realização de investimentos de alto risco visando obter um alto retorno. Dessa forma, pode-se inferir que o grupo em análise apresenta baixa propensão ao risco, de modo que tende a visar a manutenção da presente situação, ou, então, opta por auferir ganho médio, porém sujeito a um nível médio de risco.

Ainda em relação aos investimentos, observou-se que, em média, 69,8\% do lucro obtido com a pecuária leiteira é reaplicado na atividade. Nesse sentido, colocou-se para os entrevistados a oportunidade de adquirir novas terras visando a expansão do empreendimento leiteiro, de modo que $57,1 \%$ dos produtores usariam recursos próprios para a compra de terras, $33,3 \%$ não se interessariam e 9,5\% realizariam empréstimos para essa finalidade. 
Por fim, o modelo aborda a forma como o responsável pelo processo decisório na organização gerencia o risco. Assim, a Tabela 3 apresenta as respostas dos produtores acerca da consideração dos riscos envolvidos no momento da tomada de decisão.

Tabela 3 - Freqüência da consideração dos riscos para a tomada de decisão dos produtores rurais - Minas Gerais, 2005

\begin{tabular}{lc}
\hline Consideração dos riscos & Participação percentual (\%) \\
\hline Sempre & 47,6 \\
\hline Usualmente & 4,8 \\
\hline Às vezes & 28,6 \\
\hline Raramente & 19,0 \\
\hline Total & 100,0 \\
\hline
\end{tabular}

Fonte: Dados da pesquisa.

Destaca-se, portanto, que, dadas as observações até então demonstradas acerca do arriscado ambiente do negócio em questão, uma freqüência de $19 \%$ de produtores que raramente levam o risco em consideração pode ser considerada elevada. Essa informação demonstra que esse grupo não considera o gerenciamento do risco uma atividade administrativa.

A Tabela 4 retrata o grau de importância atribuído aos diversos métodos de gerenciamento de risco e sua aplicabilidade. Verifica-se que os métodos considerados muito importantes pelos entrevistados são a manutenção de reservas de alimento, apontada por todos os produtores e com total aplicabilidade, seguida da flexibilidade da produção e realização de investimentos, ambas com 90,0\% das observações e também aplicadas por todos.

Observa-se na Tabela 4 que $90 \%$ dos entrevistados consideram os contratos de venda da produção importantes ou muito importantes. Entretanto, nenhum deles faz uso de tal instrumento. Assim, espera-se que a adoção de contratos de compra e venda resulte em significativos benefícios para os produtores, principalmente no que tange à gestão do 
Sônia Maria Leite Ribeiro do Vale, Vanessa da Fonseca Pereira, Antônio Carlos Lima Neto \& Júlio César Oliveira Sant’Anna

risco. Gomes e Leite (2001) afirmam que, além de estabelecer preços ou métodos de ajuste desses a priori, esses instrumentos jurídicos podem definir parâmetros indicadores de qualidade desejáveis, quantidades mínimas e máximas a serem fornecidas, aspectos referentes ao prazo de pagamento, entre outros benefícios para ambas as partes: contratado e contratante.

Além disso, a utilização de planejamento mercadológico, a realização de parcerias entre os produtores e o cooperativismo são outras formas de minimizar as incertezas e, portanto, gerenciar o risco. Para realização de tal planejamento, é essencial a qualidade das informações disponíveis. De acordo com a Tabela 3, 85\% dos produtores afirmam que as informações de mercado são muito importantes, enquanto a utilização dessas informações como forma de resposta ao risco é feita por $76,5 \%$ dos empresários rurais. Entretanto, embora 90,5\% do grupo em análise realize planejamento, este não engloba o âmbito mercadológico, visto que se concentra na definição de questões produtivas: reforma e aquisição de benfeitorias, máquinas e equipamentos. Com isso, as informações de mercado obtidas pelos produtores podem ser usadas de modo mais sistematizado, em busca de gerar o planejamento das ações mercadológicas. 


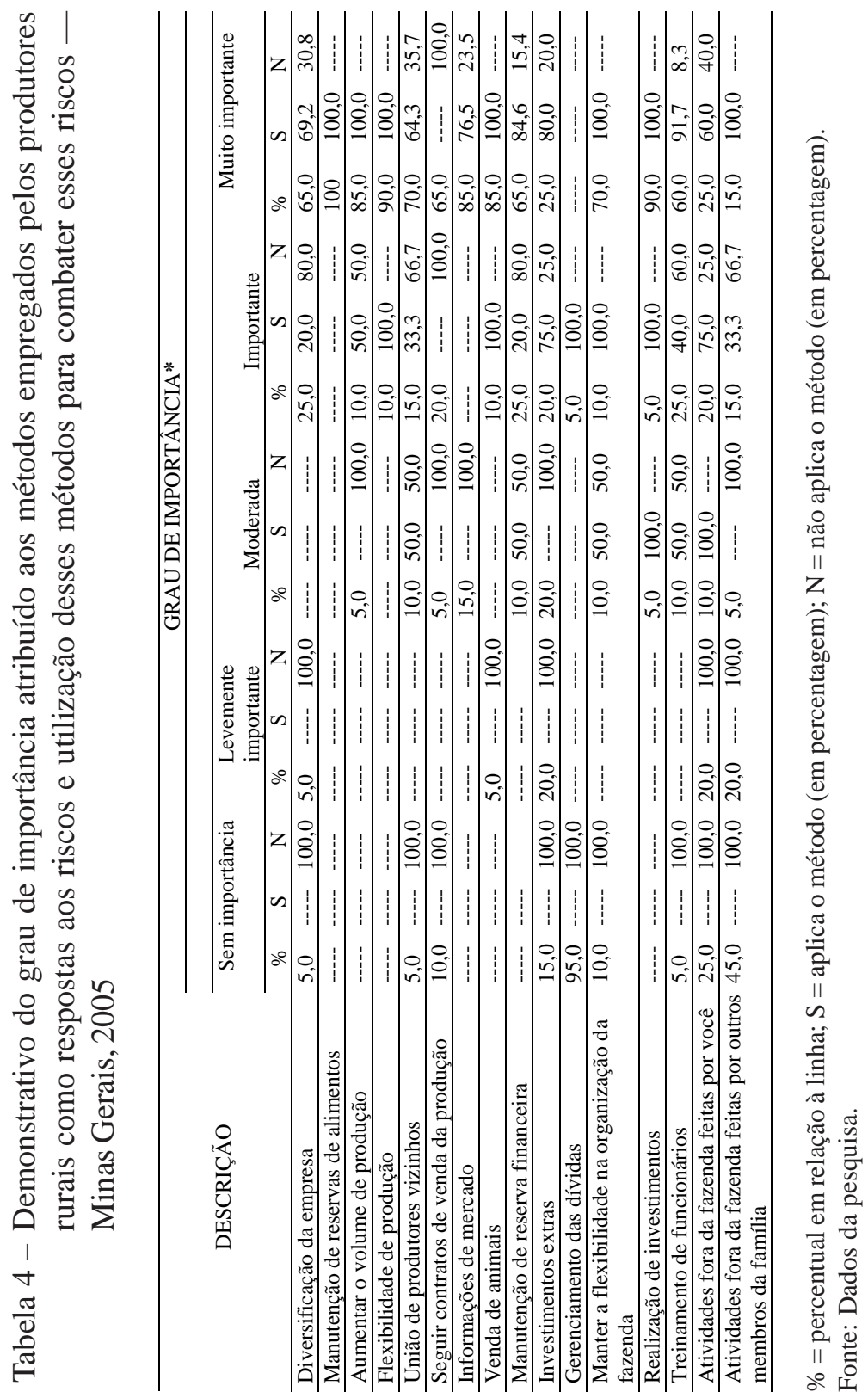


Sônia Maria Leite Ribeiro do Vale, Vanessa da Fonseca Pereira, Antônio Carlos Lima Neto \& Júlio César Oliveira Sant'Anna

A utilização de informações é fator relevante também para reduzir os impactos de possíveis eventos climatológicos. Embora seja um aspecto de elevada incerteza, há mecanismos de previsão que atuam no sentido de delinear panoramas para direcionar as ações dos empresários rurais.

Outro ponto anteriormente mencionado de importância para a redução dos impactos do risco sobre o negócio é a flexibilidade na organização da fazenda e a diversificação das atividades. Ambas apresentam significativa freqüência de importância, já que $70 \%$ dos entrevistados relacionaram a primeira como muito importante e $65 \%$, a segunda. A aplicabilidade desses métodos foi bastante alta entre os respondentes, ou seja, $100 \%$ afirmaram manter a flexibilidade na organização da fazenda e 69,2\% disseram que diversificam a empresa.

\section{Conclusões}

É importante ressaltar que o grupo de produtores em estudo faz parte do PDPL, de modo que os resultados aqui apresentados são úteis para aqueles produtores que possuem alguma assistência técnica, com acompanhamento e direcionamento de suas atividades. Quando se relacionam os métodos listados na Tabela 4 às fontes de risco apontadas como principais pelos empresários rurais abordados (Tabela 2), nota-se que a fonte apontada como mais importante é a mudança de preço do leite no mercado, seguida pela mudança dos preços dos insumos. Há, portanto, uma importante contribuição dos contratos para os produtores, e sua utilização é capaz de atuar diretamente na minimização das maiores fontes de risco, negociando-se com os fornecedores de insumos e com os compradores do leite.

Em decorrência do baixo nível de utilização de informações de mercado, é interessante que os produtores passem a fazer maior uso delas, as quais têm se tornado cada vez mais acessíveis e disponíveis. Com isso, espera-se que haja maior conhecimento do ambiente externo (mercado) e sejam reduzidas a incerteza e a suscetibilidade do produtor às oscilações 
cada vez mais constantes. Uma vez que o grupo não se apresentou propenso ao risco, a redução da incerteza é um fator que pode resultar em melhoria dos investimentos, em termos quantitativos e qualitativos.

Por fim, embora não tenha sido identificado um processo formal e planejado de gerenciamento do risco, notou-se que a atuação dos produtores, baseada principalmente em experiências anteriores, segue algumas das indicações apresentadas em diferentes trabalhos científicos. Entretanto, há ainda algumas ações que podem ser adotadas no curto prazo - contratos, planejamento mercadológico e parcerias -, as quais resultam em controles situacionais importantes para a condução do agronegócio do leite.

Além disso, as informações e análises apresentadas no presente trabalho podem ser usadas na reflexão e ação dos técnicos e consultores que atuam no setor, no sentido de auxiliar os produtores de leite no gerenciamento de sua produção, incorporando a análise de risco em suas tomadas de decisão.

\section{Referências}

BOGGESS, W.G.; KWABENA, A.A.; HANSON, G. D. Importance, causes, and management responses to farm risks: evidence from Florida and Alabama. Southern Journal of Agricultural Economics, p.105116, December, 1985.

CLEMEN, R.T. Making hard decisions: an introduction to decision analysis. Boston, M.A.: PWS - Kent Publishing Co., 1991.

GOMES, A.T.; LEITE, J.L.B. O relacionamento na cadeia agroindustrial do leite para os novos tempos. In: Embrapa - $\mathrm{O}$ agronegócio do leite no Brasil. Juiz de Fora, 2001. 
Sônia Maria Leite Ribeiro do Vale, Vanessa da Fonseca Pereira,

Antônio Carlos Lima Neto \& Júlio César Oliveira Sant'Anna

GOMES, S. T. Evolução recente e perspectivas da produção de leite no Brasil. In: EMBRAPA Gado de Leite - O agronegócio do leite no Brasil. Juiz de Fora, 2001. 262 p.

GOMES, S. T. Diagnóstico da pecuária leiteira do estado de Minas Gerais em 2005: relatório de pesquisa. Belo Horizonte: FAEMG, 2006.

IBGE-PPM - Instituto Brasileiro de Geografia e Estatística - Pesquisa da Pecuária Municipal 2005. Disponível em: 〈http://www.ibge.gov.br〉. Acesso: 01/06/2007.

HARDAKER, J.B.; HUIRNE, R.B.M.; ANDERSON J.R. Coping with risk in agriculture. Nova York: Cab International,1998.

HARRIS, S.R. Risk: perceptions and management responses in a dryland farming system, Dissertação (Bacharel em Ciência Agrícola) - University of Lincoln. 1990.

HARWOOD, $\mathrm{J}$ et al. Managing risk in farming: concepts, research and analysis. Washington: USDA, Economic Research Service, Mar. 199. 58 p. (Agricultural Economics Report, 774)

JOLLY, R. W. Risk management in agricultural production. American Agricultural Economics Association, v. 1116, p.1107-1117, 1983.

MARTIN, S. Risk perceptions and management responses to risk in New Zealand farming and agriculture. Farm Management Department, Lincoln University, Canterbury, New Zealand. 1993. 98f.

MARTIN, S. Risk management strategies in New Zealand Agriculture and Horticulture. Review of Marketing and Agricultural Economics, v. 64, n.1, p. 31-44, 1996. 
PATRICK, G. R. et al. Risk perceptions and management responses: producer-generated hypotheses for risk modeling. Southern Journal of Agricultural Economics, p. 231-238, 1985.

PINDYCK, R.S.; RUBINFELD, D.L. Microeconomia. Rio de Janeiro: Makron Books do Brasil Editora, 1994.

PORTUGAL, A. D. A cadeia produtiva do leite em 40 capítulos. In: Embrapa Gado de Leite - A cadeia produtiva do leite em 40 capítulos. Juiz de Fora, 2005. 204 p.

VALE, S.M.L.R.; SANT'ANNA, J.C.O.; LIMA NETO, A.C.S. Habilidade gerencial, metas e eficiência dos produtores de leite da Zona da Mata de Minas Gerais: relatório de pesquisa. Viçosa: FAPEMIG, 2005.

VARIAN, H.R. Microeconomia: princípios básicos. Rio de Janeiro: Campus, 1994.

\footnotetext{
Abstract - The agriculture sector has particular characteristics, general and unfavorable, which make its participants exposed to risks, and increase the complexity of making decisions. However, little is known about how farmers perceive risk in their activity. Based on a research done in the Zona da Mata region in the State of Minas Gerais, this work shows the view of a group of milk producers about the risks which they are exposed to, and also, describes the tools used by them as managing responses to these risks. Firstly, the farmers answered about the importance of the different kinds of risks in their business, and next, pointed out the methods they use to manage them. The results show the lack of a formal risk managing strategy, which has been substituted up to the moment, by the farmers' experience and, consequently, their familiarity with the marketing.

Key words: agricultural risk management, information.
} 